\title{
Nominations Sought for MRS Medal Award
}

Nominations are solicited for the MRS Medal award to be presented at the 1992 MRS Fall Meeting in Boston. The Materials Research Society established the MRS Medal, said John E.E. Baglin, chair of the MRS Medal Award Subcommittee, "with the purpose of honoring the most brilliant single events of discovery" which have a major impact on the progress of any materials-related field. "We are honoring the trail-blazers of the age of advanced materials, whose work stirs our imagination and opens fresh vistas for us all," said Baglin.

MRS Medals were presented for the first time at the 1990 MRS Fall Meeting to Prof. Arthur J. Freeman and Prof. Duward F. Shriver. Freeman, of Northwestern University's Department of Physics, was recognized for pioneering achievements in laying the foundations of the newly developing field of monolayer magnetism and artificially layered magnetic materials. Shriver, from Northwestern University's
Materials Research Center and Department of Chemistry, was honored for seminal work in the synthesis, characterization, understanding, and application of polymer-based solid electrolyte materials.

To be considered for an MRS Medal for 1991, nominations must be submitted by July 1, 1991 to: John B. Ballance, Executive Director, Materials Research Society, 9800 McKnight Road, Pittsburgh, PA 15237. Details about eligibility and nomination procedures are published elsewhere in this issue.

\section{Woody Award Goes to Sue Kelso}

Outgoing MRS President Russ Chianelli kept an interested audience and the award recipient in suspense before finally announcing that the 1990 Woody Award for extraordinary contributions to MRS would go to Sue Kelso. Kelso's face expressed complete surprise when her name was announced, leaving her "in a state of shock," as she said, recounting the event.

Kelso received the award for her "long and continuous contributions to MRS," said Chianelli. She was treasurer of MRS for four years, and has tirelessly served the organization since she first became involved. Chianelli described her as the most unselfish contributor to MRS in recent years.

"The things I did, I did because they needed to be done," Kelso said about her work with MRS, which involved negotiating a financial rollercoaster while MRS was growing exponentially. "The Society is financially solvent in large part because of her long-term commitment," said former treasurer Clif Draper.

Among many other things, Kelso also initiated the MRS constitution and bylaws and guided its re-incorporation.

She first became involved with MRS by co-chairing the 1985 Spring Meeting. "I hadn't heard of MRS until Elton [Kaufmann] called me to be a meeting chair," she said. A former Woody Award recipient, Kaufmann considers persuading Kelso to chair the meeting as his major contribution to MRS.

The Woody Award is given informally to

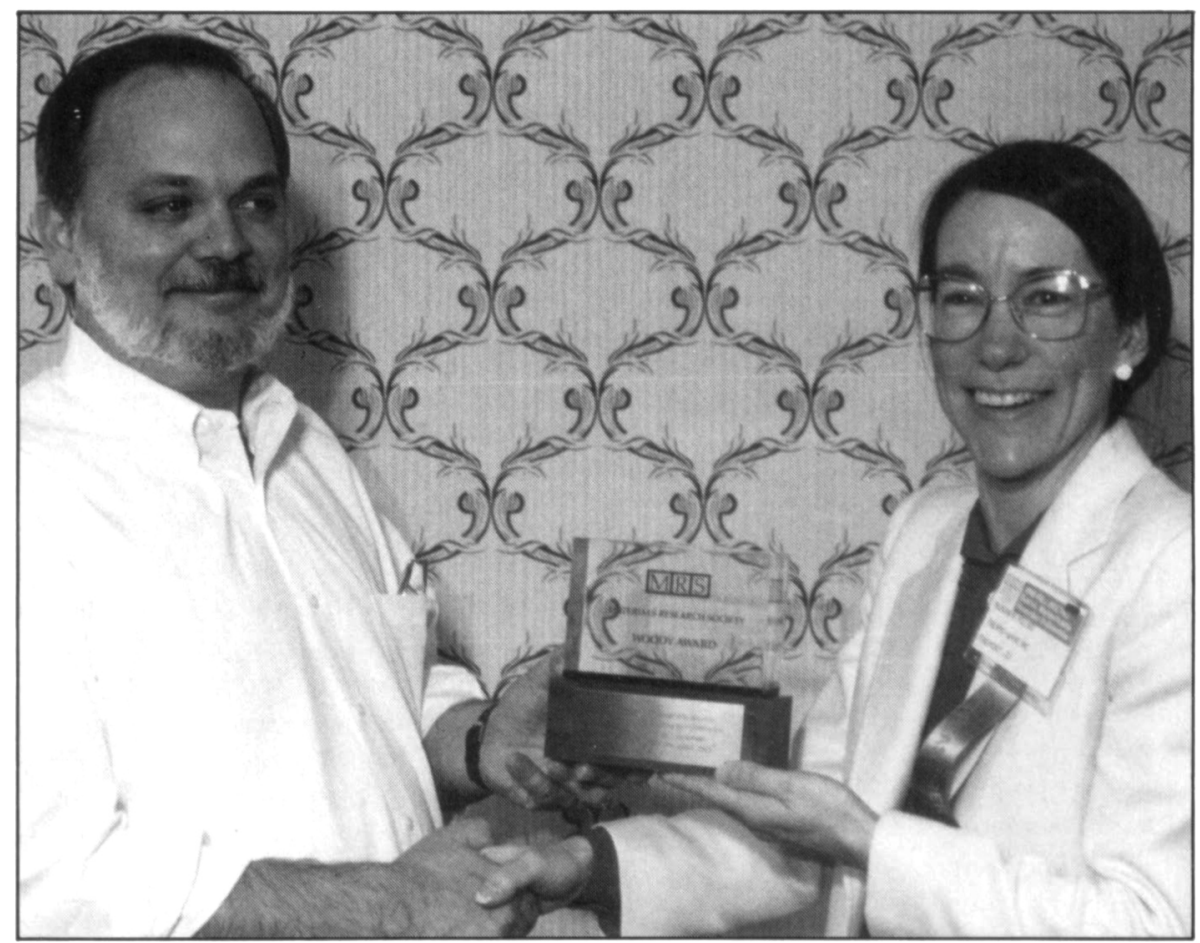

Sue Kelso (right) accepts the Woody Award from 1990 MRS President Russ Chianelli.

recognize outstanding volunteer service to MRS, above and beyond normal expectations, that has contributed to the success of the Materials Research Society. The name comes from the accomplishments achieved by Woody White during his MRS presidency in 1984.

The award was presented to Kelso at the Council dinner at the 1990 MRS Fall Meeting in Boston.

MRS 


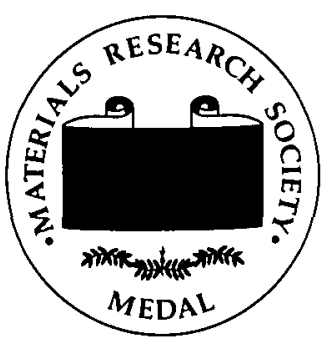

\title{
THE MRS MEDAL - 1991 \\ Public and professional recognition of an exceptional recent achievement in materials research.
}

\author{
A Medal will be awarded for a specific outstanding recent \\ discovery or advancement which is expected to have a major \\ impact on the progress of any materials-related field.
}

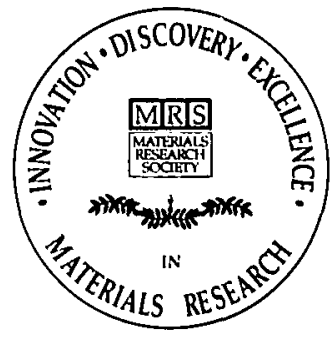

\section{THE AWARD}

Each Medal award will consist of a $\$ 1,000$ cash prize and an engraved and mounted Medal bearing a brief citation. The registration fee will be paid for each Medalist to attend the MRS Meeting at which the Medal is presented, and reasonable travel expenses will be reimbursed. Each Medalist will be invited to present a general-interest talk describing his/her work, to be featured within the structure of the Meeting.

\section{RULES AND ELIGIBILITY}

Nomination for the MRS Medalist award is open to scientists and engineers who have, in recent years, been responsible for a major advance in any materials-related field of research. The impact of their materials research upon the relevant materials field will be a primary consideration in making the awards. The Medal may recognize such impact within a larger traditional field or in a more specialized or developing field. Preference will generally be given to nominations for work which has not previously received appropriate award recognition.

A nominee need not be a member of the Materials Research Society, and nominees of any national origin or citizenship are eligible. Current members of the MRS Awards Committee and MRS Officers are not eligible. The selection of Medal winners must be approved by the Executive Committee upon recommendation from the Awards Committee; the decision of the Executive Committee is final. Medals will not be awarded in absentia except in extraordinary circumstances; a medal winner must receive his/her Medal in person at an MRS Meeting within 12 months of selection. A Medal will normally be awarded to one individual for a cited achievement. In the event that collaborators for a single achievement are each found to merit recognition on their own merits, then each may be regarded as a candidate for a Medal, and judged by the above criteria.

\section{ADMINISTRATION}

The Medalist program is managed by the Medals Subcommittee of the Awards Committee. That Subcommittee is responsible for soliciting and evaluating nominations and recommending the successful nominees to the Executive Committee for final approval. The Subcommittee consists of a Chair and three other members. Their 3-year terms of membership on the Subcommittee are staggered. Appointments to the Subcommittee are made by the President with advice from the Awards Committee Chair, and approval by the Executive Committee. The Awards Committee Chair is an ex-officio member of the Medals Subcommittee.

\section{NOMINATION PROCEDURE}

\section{A package containing the following is required for nomination for an MRS Medal:}

1. A statement by the nominator supporting the candidate's suitability for the Award with particular reference to:

- the specific, crisply defined, single recent research achievement which is proposed for recognition,

- the impact of the achievement within the relevant materials field, and its effect on other sciences,

- the innovative and perceptive quality of the candidate's work.

2. Supporting information and documents, e.g., curriculum vitae including a list of the candidate's relevant publications. Copies of up to three important papers relevant to the research achievement may also be included.

3. Letters of support from two established scientists, familiar with the nominee's qualifications and area of research. Only two such letters will be accepted with each nomination. Each letter should make specific reference to the three criteria in item 1.

4. A list of supporting documents submitted. The entire nomination package, excluding reprints, should not exceed 10 pages.

A nomination for an MRS Medal remains under consideration for three years, and may be updated by the nominator during that time.

\section{DEADLINE FOR SUBMISSION OF NOMINATIONS:}

To be considered for an MRS Medal for 1991, a nomination must be submitted by July 1, 1991 to: John B. Ballance, Executive Director, Materials Research Society, 9800 McKnight Road, Pittsburgh, PA 15237. 